\title{
CARDIAC RESYNCHRONIZATION THERAPY IN WOMEN
}

\author{
K. Sharada
}

\begin{abstract}
:
Despite underrepresentation of women in cardiac resynchronization therapy studies, it has been conclusively shown that women demonstrate greater benefit than men in functional status, reverse cardiac remodeling, and survival and female gender remains an independent predictor of greater response to cardiac resynchronization therapy after adjustment for various other factors. Eligible female patients are less likely to receive this beneficial therapy and various performance enhancement initiatives can reduce this genderbased disparity with favorable outcomes.
\end{abstract}

\section{INTRODUCTION}

Cardiac Resynchronization Therapy (CRT) is a proven modality for improving survival and reduce hospitalizations in appropriately selected heart failure (HF) patients with low ejection fraction and increased QRS duration[1-5].There are significant gender differences in prevalence of disease, physiology, body size, etiology, pathophysiology and clinical course of $\mathrm{HF}$, and many other intrinsic and extrinsic factors. Despite these disparities, present clinical practice guidelines for CRT are not gender-specific and are based on clinical trials where the majority of patients enrolled were men [6,7].In this review, we explore gender differences in clinical efficacy of CRT and reasons for this disparity.

Current professional society guidelines reserve the highest (Class I ) recommendation for CRT-defibrillator (CRT-D) implantation in patients with heart failure and reduced ejection fraction, a left bundle branch block (LBBB) and a QRS $\geq 150 \mathrm{~ms}$ [8]. For those without LBBB, the recommendations are class IIa or IIb dependent on QRS duration [8].

Article received on 8 July 2016, published on 30 July 2016 . K. Sharada ${ }^{1}$

${ }^{1}$ Specialist cardiology, AMBER Clinics, Al Rigga, Dubai, UAE

Corresponding author: K. Sharada ${ }^{1}$

Email: bksharada@yahoo.com

\section{UNDERREPRESENTATION OF WOMEN IN CLINICAL STUDIES: REASONS}

Women are underrepresented in clinical trials of CRTmaking up less than $30 \%$ of enrollees. The reasons for lesser proportion of women undergoing CRT could be due to reluctance to undergo CRT implant, concern on the part of physicians for higher procedural complications in women and more prevalence of 'heart failure with preserved ejection fraction' where CRT is not indicated[9]. Despite this fact, analysis of these clinical trials, registry data combined with many other large prospective and retrospective trials shows that women tend to do better with CRT-D than men [9].

\section{GENDER DIFFERENCES IN THE OUTCOME OF LARGE CLINICAL TRIALS (Table 1)}

The MIRACLE trial enrolled 453 patients with HF with reduced EF (<35\%), NYHA class III or IV and QRS > $130 \mathrm{~ms}$ and randomized them to CRT or control group. Women constituted $36 \%$ of the total enrolment (144/453). Improvements in both clinical status and cardiac function were seen in the CRT group. Compared with control subjects, women but not men experienced longer times to first HF hospitalization or death with CRT [10].

The Multi-centre Automatic Defibrillator Implantation Trial with Cardiac Resynchronization Therapy (MADITCRT) enrolled 1,820 patients with NYHA class I and II symptoms, $\mathrm{LVEF}<30 \%$ and QRS $>130 \mathrm{~ms}$, of whom 453 were women 9 .Patients were randomly assigned to CRT$\mathrm{D}$ or ICD alone. Patients in the CRT-D arm experienced a $34 \%$ reduction in the combined endpoint of HF or death. The study pre-specified an analysis by gender and found that the primary outcome of HF or death was seen in $11 \%$ of those with CRT-D compared with $20 \%$ with CRT-D (women: HR 0.31; $<0.001$; men: HR 0.72; $\mathrm{p}<0.01)$. The short-term gender-specific outcomes demonstrated a statistically significant reduction in mortality in women (HR 0.28; $95 \%$ CI [0.10-0.79]; $\mathrm{p}<0.02)$ but not in men (HR 1.05; $95 \%$ CI [0.70-1.57]; 
$\mathrm{p}=0.83$ ). Bit on et al. presented the results of long-term gender-specific outcomes in the MADIT-CRT population with LBBB. A total of 1,281 patients were included in this analysis, including 394 women and 887 men. Both men and women experienced a significant mortality benefit with CRT-D versus ICD only. However women had a significantly greater reduction in HF only and HF or death with CRT-D compared with men [11].

TABLE 1: Gender-related Differences in Major Trials of Cardiac Resynchronization Therapy Efficacy

\begin{tabular}{|l|l|l|l|l|l|}
\hline $\begin{array}{l}\text { Stud } \\
\text { y }\end{array}$ & $\begin{array}{l}\mathrm{n} \\
\text { Propo } \\
\text { rtion }\end{array}$ & $\begin{array}{l}\text { Treatme } \\
\text { nt arms }\end{array}$ & $\begin{array}{l}\text { LVE } \\
\text { F\% }\end{array}$ & $\begin{array}{l}\text { N } \\
\text { Y } \\
\text { H } \\
\text { A } \\
\text { Cl }\end{array}$ & $\begin{array}{l}\text { Gender based } \\
\text { Efficacy }\end{array}$ \\
\hline $\begin{array}{l}\text { MAD } \\
\text { IT- } \\
\text { CRT }\end{array}$ & $\begin{array}{l}453 \\
(25 \%)\end{array}$ & $\begin{array}{l}\text { CRT-D } \\
\text { vs ICD }\end{array}$ & $\begin{array}{l}\leq 30 \\
\%\end{array}$ & $\begin{array}{l}\text { I- } \\
\text { II }\end{array}$ & $\begin{array}{l}\text { Significantly } \\
\text { better efficacy } \\
\text { of CRT-D in } \\
\text { women than in } \\
\text { men }\end{array}$ \\
\hline $\begin{array}{l}\text { Xuet } \\
\text { al[9] }\end{array}$ & $\begin{array}{l}166 \\
(23 \%)\end{array}$ & $\begin{array}{l}\text { CRT vs } \\
\text { Medical } \\
\text { therapy }\end{array}$ & $\begin{array}{l}\leq 35 \\
\%\end{array}$ & $\begin{array}{l}\text { III } \\
-\end{array}$ & $\begin{array}{l}\text { Better efficacy } \\
\text { of CRT-D in } \\
\text { women than in } \\
\text { men }\end{array}$ \\
\hline $\begin{array}{l}\text { Leyv } \\
\text { aet } \\
\text { al[14] }\end{array}$ & $\begin{array}{l}122 \\
(22 \%)\end{array}$ & $\begin{array}{l}\text { Medical } \\
\text { therapy } \\
\text { vs } \\
\text { CRT/CR } \\
\text { T-D }\end{array}$ & $\begin{array}{l}\text { M } \\
\text { Medical } \\
\text { therapy } \\
\text { vs CRT }\end{array}$ & $\begin{array}{l}\text { III } \\
-\end{array}$ & $\begin{array}{l}\text { Greater } \\
\text { efficacy of CRT } \\
\text { in women. }\end{array}$ \\
\hline $\begin{array}{l}\text { MIR } \\
\text { ACL } \\
\text { E }\end{array}$ & $\begin{array}{l}73 \\
(32 \%)\end{array}$ & $\begin{array}{l}\text { III } \\
- \\
\text { IV }\end{array}$ & $\begin{array}{l}\text { Greater } \\
\text { efficacy of CRT } \\
\text { in women than } \\
\text { in men }\end{array}$ \\
\hline $\begin{array}{l}\text { REV } \\
\text { ERSE }\end{array}$ & $137(20$ & $\begin{array}{l}\text { CRT val } \\
\text { thera }\end{array}$ & I-II & $\begin{array}{l}\text { Better efficacy } \\
\text { in women than } \\
\text { in men }\end{array}$ \\
\hline
\end{tabular}

Foot Note: Multicenter Automatic Defibrillator Implantation Trial with Cardiac Resynchronization Therapy (MADIT-CRT)[9]; Multicenter In Sync Randomized Clinical Evaluation (MIRACLE)[10]; Resynchronization Reverses Remodeling in Systolic Left Ventricular Dysfunction (REVERSE)[12].

The Resynchronization Reverses Remodeling in Systolic Left Ventricular Dysfunction (REVERSE) trial evaluated the effects of CRT on the clinical course and LV function in patients with mild HF[12]. There were 684patients enrolled in the trial, with women constituting $20 \%$ of the total enrolment. Patients were randomized to CRT or the control group and a pre-specified analysis of 419 patients with CRT devices turned on was performed. Patients in the CRT-ON group were followed for an additional 5 years, and on multivariable analysis it was found that there was a significant survival benefit for patients with CRT-D devices compared with the control group, with the mortality benefit being larger for women than men.

$\mathrm{Xu}$ et al. retrospectively evaluated 728 patients who received CRT with the aim of detecting gender differences in CRT effectiveness. Women constituted $22.8 \%$ (166) of the total sample and had a statistically significant improvement in NYHA class that was not seen in men $(\mathrm{p}=0.009)$. A greater improvement in LVEF was also seen in women compared with men [13]. Leyva et al. studied long-term clinical outcomes after CRT implantation in 550 patients, of which 122 (22\%) were women. A Cox proportional hazards analysis showed that women had better survival from death due to any cause as well as cardiovascular death. They also had a lower incidence of the combined end point of cardiovascular death/HF hospitalizations. A greater increase in LVEF and a greater reduction in LV endsystolic volume were seen in women compared with men. These benefits were independent of QRS duration, NYHA class, LVEF, age and other comorbidities [14].

An improvement in echocardiographic parameters in women with CRT was also observed in a study by Lilli et al. They followed 195 patients for 12 months after they received CRT and found that women showed a greater benefit with CRT in the form of decreased LV end diastolic volumes and higher LVEF compared with men. This trial showed that both men and women with ICD/CRT-D derived a significant mortality benefit (men OR, 0.67; $95 \%$ CI [0.49-0.92]; $\mathrm{p}=0.0133$; women OR 0.53; $95 \%$ CI [0.31-0.91]; $\mathrm{p}=0.0227$ ), and this benefit persisted after adjusting for age [15].

\section{LBBB IN HEART FAILURE PREDICTS BETTER RESPONSE TO CRT IN WOMEN COMPARED TO MEN}

With complete LBBB, activation of the interventricular septum and left ventricular lateral wall is uncoupled, resulting in about a 100-millisecond delay between 
initial activation of the 2 walls. In contrast, in normal conduction or incomplete LBBB conduction delay, most of the left ventricle is activated synchronously via the rapidly conducting His-Purkinje system. The beneficial effect of CRT-D in LBBB likely derives from attenuating the dys-synchronous contraction caused by the large activation delay. Loring et al. showed that LBBB was associated with a significantly better survival rate in women compared with men treated with CRT. In this study of 144,642 CRT recipients, women with LBBB experienced a $26 \%$ reduction in mortality (HR 0.74; $95 \%$ CI [0.71-0.77]), while men experienced a reduction of 15 $\%$ (HR 0.85; $95 \%$ CI [0.83-0.87])after adjusting for confounding factors[16].The lack of CRT benefit in patients without LBBB has also been observed in recent studies $[9,10,12]$.

\section{GENDER DIFFERENCES IN LBBB OCCURRENCE AND NEW GENDER-SPECIFIC CRITERIA}

Women with heart failure have a higher percentage of LBBB than men (85\% vs $69 \%$ ) [6]. However, the difference is likely even greater because men have longer QRS durations than women [17] and are more likely to have a false-positive LBBB diagnosis [18]. New gender-specific strict LBBB criteria were proposed that require a QRS of 130 milliseconds or longer in women and 140 milliseconds or longer in men, along with midQRS notching and/or slurring [18]. Recent single-center studies demonstrated that patients not meeting strict LBBB criteria had a 4-fold higher rate of heart failure hospitalization or death and did not respond to CRT-D compared with patients who met the strict LBBB criteria $[19,20]$.

Patients without LBBB receiving CRT-D had a lower mortality risk than non-LBBBICD patients, although the difference was small (absolute risk difference of $2 \%$ in men and 3\% in women)[21]. A small beneficial effect of CRT has also been observed for certain patients without LBBB in previous studies and may be caused by multiple factors [22]. A recent post hoc analysis of MADIT-CRT found that patients with non-LBBB who had extremely long PR intervals at baseline benefited from CRT. This suggests that optimizing atrioventricular delay may provide some benefit in these patients [22].

\section{GENDER DIFFERENCES IN RESPONSE TO CRT WITH VARYING QRS DURATION IN LBBB}

Zusterzeel et al. [6] combined patient data from three major CRT-D versus ICD trials (MADIT-CRT, Resynchronization for Ambulatory Heart Failure Trial RAFT and REVERSE) to conduct a post-hoc metaanalysis evaluating gender-specific outcomes with CRT. The final analysis included 4,076 patients, of which $22 \%$ were women. Women with mild HF, LBBB and a QRS duration of 130-149 ms showed a $76 \%$ reduction in mortality with CRT-D (HR 0.24; $95 \%$ CI [0.06-0.89]), with no similar benefit in men with similar findings. The relationship between gender and response to CRT with varying QRS durations in patients with LBBB was further studied by Varma et al. [23].Patients with NYHA class III/IV HF, non-ischaemic cardiomyopathy and LBBB with a CRT device were followed for a period of 2 years. A total of 212 patients were enrolled of which 49.5 $\%$ (104) were women. The overall positive response rate in both genders was $76 \%$ in those with a QRS $>150 \mathrm{~ms}$, and $58 \%$ in those with a QRS $<150 \mathrm{~ms}$. However, women had a higher response rate than men at a QRS $<150 \mathrm{~ms}$ ( $86 \%$ in women versus $36 \%$ in men; $\mathrm{p}<0.001$ ). These studies indicate that the relationship between QRS duration and response to CRT is different between men and women.

One reason why women might benefit more from CRT than men at shorter QRS durations may be that women normally have shorter QRS durations than men [17]. Thus, any particular degree of QRS prolongation is relatively longer in women compared with men and may indicate greater dys-synchrony. By not considering gender-related differences in response to CRT, there is a possibility that physicians might exclude female patients with shorter QRS durations who would benefit from CRT.

\section{REASONS FOR BETTER CRT RESPONSE IN WOMEN WITH HEART FAILURE}

It is thus evident that female gender as a positive predictor of response to CRT. This is attributable to women having higher prevalence of non ischemic cardiomyopathy (55\% vs 30\%) and higher rate of 'left bundle branch block' (LBBB) configuration ( $81 \%$ vs $61 \%$ ) -both factors shown to correlate with good CRT 
response [6, 24]. Also women with HF have lower rates of atrial fibrillation/flutter (23\% vs $34 \%$ ) and ischemic HF causes which have been associated with CRT non responder state [22]. While controlling for these variables does not affect the results, it is difficult to differentiate the effect of LBBB vs non ischemic cardiomyopathy because, as demonstrated by a recent cardiac magnetic resonance study [25], complete LBBB in patients referred for ICD and CRT-D is most commonly caused by non ischemic cardiomyopathies.

\section{GENDER DIFFERENCES IN CRT UTILIZATION}

Despite the overall prevalence of HF in women being slightly less than that of men, a study sponsored by the Agency for Healthcare Research and Quality revealed that hospital admissions for HF exacerbations or HFrelated complications have been higher among female HF patients than male patients. This trend has been consistent over the past three decades [26]. Data on new CRT implantations from 2002 to 2004extracted from the Healthcare Cost and Utilization Project showed that the total number of CRTs implanted increased significantly (2,590CRT devices implanted in 2002 and 34,803 in 2004). An increase in the use of CRT was seen both in women and men; however, the increase was significantly less in women compared with men (women: 659 in2002 versus 11,286 in 2004; men: 1,931 in 2002 versus 42,196 in 2004).This disparity remained even after adjusting for the lower incidence of CHF in women. Thus despite a clear mortality benefit seen with CRT in women, this life saving therapy is still significantly underutilized in women [7].

The IMPROVE HF [27] study evaluated whether a program to provide clinical decision-making support tools and educational materials to healthcare providers would lead to similar improvements in adherence to clinical practice guidelines for both male and female patients. This was a prospective study where high-risk patients with HF with reduced $\mathrm{EF}(<35 \%)$ eligible for treatment with an ICD, CRT or several other guidelinerecommended therapies were identified and hospitals were provided with clinical algorithms, pocket cards, patient educational materials and patient assessment forms and were followed for 24 months. The study included a total of 15,170patients of whom 4,383 (28.9\%) were women. At the end of 2 years, rates of ICD use went up from $40-50 \%$ to $75-80 \%$ and CRT use from $35-$ $40 \%$ to $65-75 \%$ in both men and women. Thus, providing clinical decision-making support and education can lead to better CRT therapy utilization in eligible patients irrespective of gender.

\section{CONCLUSION}

Women are underrepresented in clinical trials of cardiac resynchronization therapy but have better prognosis than men after the device therapy and special efforts should be directed at reaching women for this lifesaving therapy.

\section{REFERENCES}

1. Moss AJ, Hall WJ, Cannom DS, et al; MADIT-CRT Trial Investigators. Cardiac resynchronization therapy for the prevention of heart-failure events. N Engl J Med. 2009; 361: 1329-1338.

2. Tang AS, Wells GA, Talajic $\mathrm{M}$, et al; Resynchronization-Defibrillation for Ambulatory Heart Failure Trial Investigators. Cardiac-resynchronization therapy for mild-to-moderate heart failure. $\mathrm{N}$ Engl J Med. 2010; 363: 2385-2395

3. Linde C, Abraham WT, Gold MR, et al; REVERSE (Resynchronization reverses Remodeling in Systolic left vEntricular dysfunction) Study Group. Randomized trial of cardiac resynchronization in mildly symptomatic heart failure patients and in asymptomatic patients with left ventricular dysfunction and previous heart failure symptoms. J Am CollCardiol. 2008; 52: 1834-1843.

4. Bristow MR, Saxon LA, Boehmer J, et al. Comparison of Medical Therapy, Pacing, and Defibrillation in Heart Failure (COMPANION) Investigators. Cardiacresynchronization therapy with or without an implantable defibrillator in advanced chronic heart failure. N Engl J Med. 2004; 350: 2140-2150.

5. Cleland JG, Daubert JC, Erdmann E, et al; Cardiac Resynchronization-Heart Failure (CARE-HF) Study Investigators. The effect of cardiac resynchronization on morbidity and mortality in heart failure. N Engl J Med. 2005; 352: 1539-1549. 
6. Zusterzeel R, Selzman KA, Sanders W, et al. Cardiac Resynchronization Therapy in women. US Food and Drug Administration meta-analysis of patient level data. JAMA Intern Med 2014; 174: 1340-1348.

7. Narasimha D, Curtis AB. Sex Differences in Utilization and Response to Implantable Device Therapy. Arrhythmia \& Electrophysiology Review 2015; 4: 129-35.

8. Tracy CM, Epstein AE, Darbar D, et al. 2012 ACCF/AHA/HRS Focused Update of the 2008 Guidelines for Device-Based Therapy of Cardiac Rhythm Abnormalities: a report of the American College of Cardiology Foundation/American Heart Association Task Force on Practice Guidelines. Heart Rhythm. 2012.

9. Arshad A, Moss AJ, Foster E, et al; MADIT-CRT Executive Committee. Cardiac resynchronization therapy is more effective in women than in men: the MADIT-CRT (Multicenter Automatic Defibrillator Implantation Trial with Cardiac Resynchronization Therapy) trial. J Am CollCardiol. 2011; 57:813-820.

10. Woo GW, Petersen-Stejskal S, Johnson JW, et al. Ventricular reverse remodeling and 6-month outcomes in patients receiving cardiac resynchronization therapy: analysis of the MIRACLE Study. J Intervent Card Elect 2005; 12: 107-13.

11. Biton Y, Zareba W, Goldenberg I, et al. Sex differences in long-term outcomes with cardiac resynchronization therapy in mild heart failure patients with left bundle branch block. J Am Heart Assoc 2015; $4(7)$.

12. Gold MR, Daubert JC, Abraham WT, et al. Implantable defibrillators improve survival in patients with mildly symptomatic heart failure receiving cardiac resynchronization therapy: Analysis of the long-term follow-up of remodeling in systolic left ventricular dysfunction (REVERSE). Circ Arrhythm Electro physiol 2013; 6: 1163-1168.

13. Xu YZ, Friedman PA, Webster $\mathrm{T}$, et al. Cardiac resynchronization therapy: do women benefit more than men? J CardiovascElectrophysiol 2012; 23: 172-178.
14. Leyva F, Foley PW, Chalil S, et al. Female gender is associated with a better outcome after cardiac resynchronization therapy. Pacing ClinElectrophysiol 2011; 34: 82-88.

15. Lilli A, Ricciardi G, Porciani MC, et al. Cardiac esynchronization therapy: gender related differences in left ventricular reverse remodeling. Pacing ClinElectrophysiol 2007; 30: 1349-1355.

16. Loring Z, Caños DA, Selzman K, et al. Left bundle branch block predicts better survival in women than men receiving cardiac resynchronization therapy: longterm follow-up of $\sim 145,000$ patients. JACC Heart Fail 2013; 1: 2372-44.

17. Macfarlane P, Van Oosterom A, Pahlm O, et al. Appendix 1: adult normal limits. In: Macfarlane P, Van Oosterom A, Pahlm O, et al, eds. Comprehensive Electrocardiology. Vol 4. 2nd ed. London, England: Springer-Verlag; 2011: 2057-2126.

18. Strauss DC, Selvester RH, Wagner GS. Defining left bundle branch block in the era of cardiac resynchronization therapy. Am J Cardiol 2011; 107: 927934.

19. Mascioli G, Padeletti L, Sassone B, et al. Electrocardiographic criteria of true left bundle branch block: a simple sign to predict a better clinical and instrumental response to CRT. Pacing ClinElectrophysiol 2012; 35: 927-934.

20. Tian Y, Zhang P, Li X, et al. True complete left bundle branch block morphology strongly predicts good response to cardiac resynchronization therapy. Europace 2013; 15: 1499-1506.

21. Loring Z, Strauss DG, Gerstenblith G, et al. Cardiac MRI scar patterns differ by sex in an implantable cardioverter-defibrillator and cardiac resynchronization therapy cohort. Heart Rhythm.2013; 10: 659-65.

22. Kutyifa V, Stockburger M, Daubert JP, et al. PR interval identifies clinical response in patients with nonleft bundle branch block: a Multicenter Automatic Defibrillator Implantation Trial-Cardiac Resynchronization Therapy substudy. Circ Arrhythm Electrophysiol. 2014; 7: 645-651. 
23. Varma N, Manne M, Nguyen D, et al. Probability and magnitude of response to cardiac resynchronization therapy according to QRS duration and gender in nonischemic cardiomyopathy and LBBB. Heart Rhythm 2014; 11: 1139-1147.

25. Strauss DG, Loring Z, Selvester RH, et al. Right, but not left, bundle branch block is associated with large anteroseptal scar. J Am CollCardiol 2013; 62: 959-967.

24. Zusterzeel R, Spatz ES, Curtis JP, et al. Cardiac resynchronization therapy in women vs men. Observational comparative effectiveness study from the national cardiovascular data registry.CircCardiovascQual Outcomes 2015; 8: S4-S11.
26. Herz ND, Engeda J, Zusterzeel R, et al. Sex differences in device therapy for heart failure: utilization, outcomes, and adverse events. J Womens Health (Larchmt) 2015; 24 :261-71.

27. Walsh MN, Yancy CW, Albert NM, et al. Equitable improvement for women and men in the use of guideline recommended therapies for heart failure: findings from IMPROVE HF. J Card Fail 2010; 16: 940949. 